\title{
Induction of HBF
}

\section{Mehran Karimi, Nader Cohan \\ Hematology Research Center, Nemazee Hospital, Shiraz University of Medical Sciences, Shiraz-Iran}

\begin{abstract}
The role of $\mathrm{HbF}$ inducers in ameliorating the pathophysiology and severity associated with hemoglobinopathies like sickle cell disease and thalassemia is well demonstrated. So many studies have focused on explain the pathways that involved in the re-activation of $\gamma$-globin gene expression. The HbF inducers are mainly includes chemotherapeutic agents (e.g. 5-Azacytidine and hydroxyurea), short-chain fatty acid derivatives (e.g. butyrates, valporate, sodium phenylbutyrate) and other $\mathrm{HbF}$ inducers like stem cell factor and synthetic gene-targeted transcription factors. These $\mathrm{HbF}$ inducers have significant effects on improve clinical manifestations of hemoglobinopathies and decreasing transfusion dependency. But regarding some limitations of these agents, more studies for the investigation of new agents with more safety and effectiveness is needed.
\end{abstract}

\section{Introduction}

Different hemoglobin's (Hbs) are synthesized during the different parts of human life's including embryonic, fetus and adult life. All of this Hbs are structurally same by the tetrameric protein globin chains (made up of two different pairs) which one heme molecule attached to each of globin changes. The embryonic Hbs includes Hb Gower 1 ( $₹ 2$ $\varepsilon 2)$, Hb Portland ( $\xi 2 \gamma 2$ ), and Hb Gower 2 ( $\alpha 2 \varepsilon 2$ ). The embryonic Hb switch occurs at approximately 6 to 8 weeks which switch from embryonic $\mathrm{Hbs}$ to fetal $\mathrm{Hb}(\mathrm{Hb} \mathrm{F}(\alpha 2 \gamma 2))$ and then the fetal switch which occurs in the prenatal period to switch from fetal $\mathrm{Hb}$ to adult $\mathrm{Hb}(\mathrm{Hb}$ $\mathrm{A}(\alpha 2 \beta 2))$. (1,2) In the fetal life, $\mathrm{HbF}$ is the predominant $\mathrm{Hb}$ but it's

Correspondence: Mehran Karimi

Key words: HbF inducer, hemoglobinopathy, $\curlyvee$-globin gene, re-activation.

Conflict of interest: none.

CCopyright M. Karimi, 2013

Licensee PAGEPress, Italy

Thalassemia Reports 2013; 3(s1):e39

doi:10.4081/thal.2013.s1.e39

This article is distributed under the terms of the Creative Commons Attribution Noncommercial License (by-nc 3.0) which permits any noncommercial use, distribution, and reproduction in any medium, provided the original author(s) and source are credited.

Parts of this work were presented at the

" 3 rd Pan-European Conference on Haemoglobinopathies and Rare Anaemias", Limassol (Cyprus), 24-26 October 2012. largely replaced by $\mathrm{HbA}$ after fetal switching so that it's composed less than $1 \%$ of adult $\mathrm{Hb}$ but, in some hemoglobin disorders which abnormal globin chain is $\beta$-subunit like sickle cell disease and beta-thalassemia this proportion may increased. Also it is well documented that increased $\mathrm{HbF}$ will ameliorate the pathophysiology and severity associated with these hemoglobinopathies $(3,4)$ so, many researches has focused on explain the pathways that involved in the re-activation of $\gamma$-globin gene expression and consequently increased the $\mathrm{HbF}$ level in order to decreased the clinical manifestations and severity of these hemoglobinopathies.

\section{Gama-globin gene structure and regulation}

The human $\gamma$-globin gene in belong to $\beta$-globin locus which consisting of about $100 \mathrm{~kb}$ and located on chromosome 11. The $\beta$-globin locus is also consists of $\varepsilon$, and $\beta$ genes by arranged in the order corresponding to their progressive expression during development $\left(5^{\prime}-\varepsilon-\mathrm{G} \gamma-\mathrm{A} \gamma-\psi\right.$ $\left.\beta--\beta-3^{\prime}\right)(5)$. HbF is composed of two types of $\gamma$ chains that differ in their number 136 amino acid including: glycine or alanine (G $\gamma$ and $A \gamma)$ which are the products of separate globin gene loci. The relative synthesis of $\mathrm{G} \gamma / \mathrm{A} \gamma$ ratio changed from $3 / 1$ in fetal life to $2 / 3$ in adults (1). The $\gamma$-globin gene codes the $\gamma$-globin chain which consists of 146 amino acids. By the age of 9-24 months the $\mathrm{HbF}$ completely repressed and the residual amount of $\mathrm{HbF}$ is controlled genetically (6). So, patients with $\beta$-thalassemia don't usually present clinical manifestations at birth until fetal globin gene become fully silent or repressed which it usually occurs between 9-24 months of age. Finding the genetic variants associated with variations in $\mathrm{HbF}$ levels were done by genome-wide association (GWA) studies (7). These studies have founded polymorphisms in 3 loci (quantitative trait loci: QTLs) that account as a major heritable variation $(\sim 50 \%)$ in $\mathrm{HbF}$ expression in adults which includes: the $\beta$-globin locus on chromosome 11, HBS1L-MYB intergenic region on chromosome 6 and the gene encoding BCL11A on chromosome 2 (7-11). MYB is known to have a critical role in erythropoiesis. Transcription factors BCL11A, SOX6 and KLF1 are the key regulators of the $\gamma$-globin gene suppression and $\mathrm{HbF}$ gene switching (12-14).

\section{Clinical experience in using $\mathrm{HbF}$ inducers}

Re-activation of $\gamma$-globin gene expression, resulting in increased $\mathrm{HbF}$, is a good treatment approach in patients with $\beta$-thalassemia. Because of long term treatment for patients with $\beta$-thalassemia, $\mathrm{HbF}$ inducers should have some characteristics including to be orally, active, tolerable with minimal side effects and also must not inhibit erythropoeisis or to be mutagenic.

Three classes of potential HbF-inducing therapeutic agents have been investigated for the treatment of hemoglobinopathies disorders which includes: Chemotherapeutic agents, short-chain fatty acid derivatives (SCFDAs) and other HbF switchers (8). 


\section{Chemotherapeutic agents}

5-Azacytidine (5-Aza) and its safer derivative decitabine was the first agent that shown to have ability in re-activation of $\mathrm{HbF}$ synthesis in human that used for the treatment of $\beta$-thalassemia and sickle cell disease (13). Although the exact mechanism of 5-Aza in re-activation of $\mathrm{HbF}$ synthesis is unclear but it may be related to its ability to act as an S-phase cell-cycle inhibitor (14).

Hydroxyurea (HU) is a ribonucleotide reductase inhibitor that first approved for clinical use in sickle cell anemia patients as a $\mathrm{HbF}$ inducer (15). Although the exact mechanism of $\mathrm{HU}$ in induction of $\mathrm{HbF}$ is still unclear but recent studies demonstrated that HU leads to substantial changes in erythroid gene expression, including decreased expression of BCL11A and S0X6 which are the key regulators of the $\gamma$-globin gene (12). Its effects in $\beta$-thalassemia patients have been extensively studied and according to the majority of them, it has significant clinical and paraclinical hematological effects in patients with thalassemia intermedia, and it is also safe with minimal side effects with decreased or unneeded transfusion dependency (16-19).

\section{Short-chain fatty acid derivatives}

They includes: butyrate, sodium phenylbutyrate, valproate, and isobutyramide that have an effect on induction of $\mathrm{HbF}$ and produced clinical effects in small clinical trials (20). Some of these products including sodium phenylbutyrate, arginine butyrate, and isobutyrate are histone deacetylase (HDAC) inhibitors. These products increased $\gamma$-globin gene expression by opening up the chromatin and increasing accessibility of transcription factors through inhibition of $\operatorname{HDAC}(8,21)$. SCFADs can increase $\mathrm{Hb}$ by $2 \mathrm{gr} / \mathrm{dl}$ in $50 \%$ of untransfused patients. RB7 is a new generation of SCFADs with higher potency than butyrate, taken orally and active at low concentration (22).

\section{Other HbF switchers}

They includes: stem cell factor, Thalidomide, Lenalidomide, Pomalidomide and recently defined synthetic gene-targeted transcription factors that bind to specific DNA sequences to regulate the expression of endogenous genes and can induce the expression of $\gamma$-globin gene $(5,23)$. Natural world components like Rapamycin and Resveratrol are other $\mathrm{HbF}$ inducers that they are not associated with cytotoxic or cell growth inhibitors. Erythropoietin is also $\mathrm{HbF}$ inducer that promotes red blood cells survival and cause increased $\mathrm{Hb}$ levels in some patients with $\beta$-thalassemia but it has some risks due to erythroid expansion and increased intestinal iron absorption and extramedullary hematopoiesis (8).

\section{Conclusions}

Many studies regarding the effects of $\mathrm{HbF}$ inducers in hemoglobinopathies demonstrated the rational approach for the management of these disorders although these therapies have some limitations like don't response all of patients to these agents, inhibit erythroid proliferation by cytotoxic agents and their potentially mutagenic, need to frequent administration and high doses of short-chain fatty acid derivatives because of their rapid metabolism and also increase iron absorption and extramedullary hematopoiesis by use of erythropoietin (8).
Several novel $\mathrm{HbF}$ inducers are in clinical experimental study including; novel SCFADs like sodium 2,2-dimethylbutyrate and $\alpha$-methylhydrocinnamate, Rapamycin and Resveratol as natural products and finding specific targets that have a role in the erythroid regulatory pathway. So, regarding the significant effects of fetal hemoglobin inducers in improving clinical manifestations of hemoglobinopathies and also decrease the transfusion dependency and consequently financial costbenefit of $\mathrm{HbF}$ inducers, more studies are needed to investigate the new agents with more safety and effectiveness.

\section{References}

1. Thein SL. Rees D. Haemoglobin and the inherited disorders of globin synthesis. In: Hoffbrand V, Catovsky D, Tuddenham E, Green A. Post graduate haematology. Sixth edition, Blackwell Publishing, 201;83-108.

2. Muncie HL, Jr., Campbell J. Alpha and beta thalassemia. Am Fam Physician 2009;80(4):339-44.

3. Sankaran VG, Nathan DG. Reversing the hemoglobin switch. N Engl J Med 2010;363:2258-2260.

4. Olivieri NF. The beta-thalassemias. N Engl J Med 1999;341:99-109.

5. Testa U. Fetal hemoglobin chemical inducers for treatment of hemoglobinopathies. Ann Hematol 2009;88:505-528.

6. Garner C, Tatu T, Reittie J.E, Littlewood T, Darley J, Cervino S, et al. Genetic influences on F cells and other hematologic variables: a twin heritability study. Blood 2000;95:342-346.

7. Uda M, Galanello R, Sanna S, Lettre G, Sankaran VG, Chen W, et al. Genome-wide association study shows BCL11A associated with persistent fetal hemoglobin and amelioration of the phenotype of beta-thalassemia. Proc Natl Acad Sci U S A 2008;105:1620-1625.

8. Thein SL. The emerging role of fetal hemoglobin induction in nontransfusion-dependent thalassemia. Blood Reviews 2012;26S:S35S39.

9. Sankaran VG. Targeted therapeutic strategies for fetal hemoglobin induction. Hematology Am Soc Hematol Educ Program 2011;2011: 459-65.

10. Menzel S, Garner C, Gut I, Matsuda F, Yamaguchi M, Heath S, et al. A QTL influencing $\mathrm{F}$ cell production maps to a gene encoding a zinc-finger protein on chromosome 2p15. Nat Genet 2007;39(10): 1197-9.

11. Zhou D, Liu K, Sun C.W, Pawlik K.M, Townes T.M. KLF1 regulates BCL11A expression and gamma- to beta-globin gene switching. Nature Genetics 2010;42:742-744.

12. Flanagan JM, Steward S, Howard TA, Mortier NA, Kimble AC, Aygun $\mathrm{B}$, et al. Hydroxycarbamide alters erythroid gene expression in children with sickle cell anaemia. Br J Haematol 2012;157(2):240-8.

13. Dover GJ, Charache SH, Boyer SH, Talbot CC, Smith KD. 5Azacytidine increases fetal hemoglobin production in a patient with sickle cell disease. Progr Clin Biol Res 1983;134:475- 488.

14. Sankaran VG, Nathan DG. Thalassemia: an overview of 50 years of clinical research. Hematol Oncol Clin North Am. 2010;24:10051020.

15. Platt OS. Hydroxyurea for the treatment of sickle cell anemia. $\mathrm{N}$ Engl J Med 2008 27;358(13):1362-9.

16. Karimi M, Haghpanah S, Farhadi A, Yavarian M. Genotype-phenotype relationship of patients with $\beta$-thalassemia taking hydroxyurea: a 13-year experience in Iran. Int J Hematol 2012;95(1):51-6.

17. Amoozgar H, Farhani N, Khodadadi N, Karimi M, Cheriki S. Comparative study of pulmonary circulation and myocardial function in patients with $\beta$-thalassemia intermedia with and without hydroxyurea, a case-control study. Eur J Haematol 2011;87(1):61-7. 18. Karimi M, Cohan N, Mousavizadeh K, Falahi MJ, Haghpanah S. 
Adverse effects of hydroxyurea in beta-thalassemia intermedia patients: 10 years' experience. Pediatr Hematol Oncol 2010;27(3):205-11.

19. Karimi M. Hydroxyurea in the management of thalassemia intermedia. Hemoglobin 2009;33 Suppl 1:S177-82.

20. Boosalis MS, Castaneda SA, Trudel M, Mabaera R, White GL, Lowrey $\mathrm{CH}$, et al. Novel therapeutic candidates, identified by molecular modeling, induce $\gamma$-globin gene expression in vivo. Blood Cells Mol Dis 2011 15;47(2):107-16.

21. Boosalis MS, Bandyopadhyay R, Bresnick EH, Pace BS, Van DeMark K, Zhang B, et al. Short-chain fatty acid derivatives stimu- late cell proliferation and induce STAT-5 activation. Blood 2001;97(10): 3259-67.

22. Mankidy R, Faller DV, Mabaera R, Lowrey CH, Boosalis MS, White $\mathrm{GL}$, et al. Short-chain fatty acids induce gamma-globin gene expression by displacement of a HDAC3-NCoR repressor complex. Blood 2006 1;108(9):3179-86.

23. Costa FC, Fedosyuk H, Neades R, de Los Rios JB, Barbas CF 3rd, Peterson KR. Induction of Fetal Hemoglobin In Vivo Mediated by a Synthetic $\gamma$-Globin Zinc Finger Activator. Anemia 2012;2012: 507894.

\section{Oral presentation}

Oral presentation is available online 